\title{
Pretransplant Immune- and Apoptosis-Related Gene Expression Is Associated with Kidney Allograft Function
}

\author{
Dorota Kamińska, ${ }^{1}$ Katarzyna Kościelska-Kasprzak, ${ }^{1}$ \\ Paweł Chudoba, ${ }^{2}$ Oktawia Mazanowska, ${ }^{1}$ Mirosław Banasik, ${ }^{1}$ Marcelina Żabinska, ${ }^{1}$ \\ Maria Boratyńska, ${ }^{1}$ Agnieszka Lepiesza, ${ }^{2}$ Agnieszka Gomółkiewicz, ${ }^{3}$ \\ Piotr Dzięgiel, ${ }^{3}$ and Marian Klinger ${ }^{1}$
}

${ }^{1}$ Department of Nephrology and Transplantation Medicine, Wroclaw Medical University, 52-129 Wrocław, Poland

${ }^{2}$ Department of Vascular, General and Transplant Surgery, Wroclaw Medical University, 52-129 Wrocław, Poland

${ }^{3}$ Department of Histology and Embryology, Wroclaw Medical University, 50-368 Wrocław, Poland

Correspondence should be addressed to Dorota Kamińska; dorotakaminska@interia.pl

Received 29 February 2016; Revised 22 April 2016; Accepted 9 May 2016

Academic Editor: Simi Ali

Copyright (C) 2016 Dorota Kamińska et al. This is an open access article distributed under the Creative Commons Attribution License, which permits unrestricted use, distribution, and reproduction in any medium, provided the original work is properly cited.

Renal transplant candidates present immune dysregulation, caused by chronic uremia. The aim of the study was to investigate whether pretransplant peripheral blood gene expression of immune factors affects clinical outcome of renal allograft recipients. Methods. In a prospective study, we analyzed pretransplant peripheral blood gene expression in 87 renal transplant candidates with real-time PCR on custom-designed low density arrays (TaqMan). Results. Immediate posttransplant graft function (14-day GFR) was influenced negatively by TGFB1 $(P=0.039)$ and positively by $I L-2$ gene expression $(P=0.040)$. Pretransplant blood mRNA expression of apoptosis-related genes (CASP3, FAS, and IL-18) and Th1-derived cytokine gene IFNG correlated positively with short- (6-month GFR CASP3: $P=0.027, F A S: P=0.021$, and IFNG: $P=0.029)$ and long-term graft function (24-month GFR CASP3: $P=0.003, F A S: P=0.033, I L-18: P=0.044$, and IFNG: $P=0.04)$. Conclusion. Lowered pretransplant Th1-derived cytokine and apoptosis-related gene expressions were a hallmark of subsequent worse kidney function but not of acute rejection rate. The pretransplant IFNG and CASP3 and FAS and $I L-18$ genes' expression in the recipients' peripheral blood is the possible candidate for novel biomarker of short- and long-term allograft function.

\section{Introduction}

Kidney transplantation outcome depends on many immunological and nonimmunological factors. Renal transplant candidates present immune dysregulation, caused by chronic uremia followed by renal replacement therapy [1]. Recently, uremia was reported to influence cytokine synthesis [2]. While the immune response shift is well described in the literature, still it is not clear whether the pretransplant chronic inflammation affects posttransplant outcome. From routine blood tests CRP (C-reactive protein) and albumin levels were shown not only to reflect the general immune response in uremic patients [3] but also to predict kidney outcome $[4,5]$.
Pretransplant cytokine profiles were also considered to exert a deleterious effect on graft function or survival, but the published data have been inconclusive $[6,7]$.

The aim of the study was to investigate whether pretransplant peripheral blood gene expression affects clinical outcome of renal allograft recipients. In a prospective study we analyzed a wide range of immune factors known to be related to inflammation (IL-6, IL-8, NGAL, and TNF-alpha), apoptosis (Fas, caspase 3, p53, and IL-18), and lymphocyte $\mathrm{T}$ activation (IFN-gamma, IL-2) as well as regulatory $\mathrm{T}$ cell (IL-10, TGF-beta, and Foxp3) function with the real-time PCR method. Pretransplant cytokine gene expression linked to recipient- and donor-related factors was examined with further analysis of allograft function. The working hypothesis 
was the search for the novel predictive biomarkers connecting the recipients' pretransplant immune and inflammatory status with transplant outcome.

\section{Patients}

The study was carried out prospectively on 87 low risk consecutive renal transplant recipients (aged 16-72 years, mean 47 years; 34 females, 53 males) transplanted between 2006 and 2012 at Wroclaw Medical University. Among them 66 patients were treated with hemodialysis and 21 patients with peritoneal dialysis. They remained on renal replacement therapy from 1 to 97 months (mean $25 \pm 18$ months).

The patients received organs from donors (81 deceased, 6 living) aged from 16 to 72 years. Eighty-three recipients received their first graft, while for 4 of them it was the second transplant. They were being transplanted after cold ischemia time from 9 to 45 hours. Three recipients presented pretransplant panel reactive antibodies (PRA) above $20 \%$.

Immunosuppressive therapy consisted of corticosteroids with cyclosporine and mycophenolate mofetil/sodium in 35 cases, corticosteroids with tacrolimus and mycophenolate mofetil/sodium in 49 cases, corticosteroids with everolimus and tacrolimus in 1 case, and corticosteroids with sirolimus and cyclosporine in 2 cases. Four recipients received induction therapy with anti-CD25 antibodies at the time of transplantation. Donor and recipient characteristics are presented in Table 1.

Pretransplant demographic and clinical data (age, gender, weight, height, comorbidity, and history of chronic kidney disease) were obtained from medical records from patients' dialysis centers. Posttransplant clinical data (renal function, immunosuppressive therapy, complications, and outcome) were collected from medical records of the transplant outpatient clinic of the Department of Nephrology and Transplantation Medicine in Wroclaw, Poland. Estimated glomerular filtration rate (eGFR) was calculated using the abbreviated Modification of Diet in Renal Disease study formula (MDRD).

Blood samples for routine laboratory tests assessing pretransplant inflammatory response as well as samples for gene expression were collected immediately before the transplant procedure and introduction of immunosuppressive therapy. Posttransplant laboratory tests were completed during routine visits to an outpatient clinic.

The study was approved by the Commission of Bioethics at Wroclaw Medical University, and all aspects of the study were in accordance with the World Medical Association Declaration of Helsinki. Before enrollment, each patient read an information sheet and provided fully informed consent.

\section{Methods}

The peripheral blood samples were obtained with PAXgene Blood RNA tubes. RNA was isolated with a PAXgene Blood RNA kit (PreAnalytics) and reversely transcribed with High Capacity RNA to cDNA kit (Applied Biosystems). The peripheral blood gene expression of caspase-3 (CASP3, Hs00263337_ml), Fas (FAS, Hs00236330_ml), p53 (TP53,
TABLE 1: Donor and recipient characteristics (mean \pm SD or number of cases).

\begin{tabular}{|c|c|}
\hline \multicolumn{2}{|l|}{ Recipients } \\
\hline Recipient age (years) & $47 \pm 14$ \\
\hline Recipient gender (female/male) & $34 / 53$ \\
\hline Dialysis (HD/PD) & $66 / 21$ \\
\hline Time of dialysis (months) & $33 \pm 42$ \\
\hline BMI $\left(\mathrm{kg} / \mathrm{m}^{2}\right)$ & $24.6 \pm 3.6$ \\
\hline Last PRA > 20\% & 3 \\
\hline \multicolumn{2}{|l|}{ Primary kidney disease } \\
\hline Diabetic nephropathy & 9 \\
\hline Chronic glomerulonephritis & 34 \\
\hline Hypertensive nephropathy & 16 \\
\hline Polycystic renal disease & 10 \\
\hline Chronic interstitial nephritis & 14 \\
\hline Other/unknown & 4 \\
\hline \multicolumn{2}{|l|}{ Donors } \\
\hline Donor age (years) & $45 \pm 13$ \\
\hline Donor gender (female/male) & $34 / 53$ \\
\hline CIT (hours) & $25.1 \pm 6.9$ \\
\hline \multicolumn{2}{|l|}{ Number of HLA mismatches } \\
\hline 0 & 2 \\
\hline 1 & 1 \\
\hline 2 & 13 \\
\hline 3 & 28 \\
\hline 4 & 33 \\
\hline 5 & 9 \\
\hline 6 & 1 \\
\hline
\end{tabular}

Hs00153349_m1), Foxp3 (FOXP3, Hs00203958_m1), IFNgamma (IFNG, Hs00174143_m1), interleukin-2 (IL-2, Hs00174114_m1), interleukin-6 (IL-6, Hs00174131_m1), interleukin-8 (IL-8, Hs00174103_m1), interleukin-10 (IL-10, Hs00174086_m1), interleukin-17 (IL-17A, Hs99999082_m1), interleukin-18 (IL-18, Hs00155517_ml), NGAL (LCN2, Hs00194353_m1), TGF-beta (TGFB1, Hs99999918_m1), and TNF-alpha (TNF, Hs00174128_ml) was assessed with realtime PCR on custom-designed low density arrays (TaqMan) with TaqMan PCR Master Mix. All procedures were performed according to the manufacturer's protocols.

GAPDH was chosen as the reference gene, and it was proved not to be related to transplant outcome (delayed graft function (DGF)/acute rejection occurrence (AR), serum creatinine, and GFR).

Each gene was tested in triplicate; raw expression data were averaged and converted to $\Delta \mathrm{Ct}$, where $\Delta \mathrm{Ct}=\mathrm{Ct}_{\text {gene }}-$ $\mathrm{Ct}_{\mathrm{GAPDH}}$ and $\mathrm{Ct}$ is the cycle threshold value and defines the calculated cycle number, in which the fluorescence measured during PCR reaction increases over the preset threshold value.

The expression data were analyzed separately for each of the genes in the subsequent manner. The samples with the highest quartile of $\Delta \mathrm{Ct}$ values (which corresponds to the lowest expression level) were chosen as a reference group (ref) 
TABLE 2: Pretransplant recipient blood parameters.

\begin{tabular}{lc}
\hline & Mean \pm SD \\
\hline Hgb $(\mathrm{g} / \mathrm{dL})$ & $11.1 \pm 1.7$ \\
WBC count $\left(\times 10^{3} / \mathrm{mcL}\right)$ & $7.4 \pm 2.3$ \\
PLT count $\left(\times 10^{3} / \mathrm{mcL}\right)$ & $198 \pm 64$ \\
CRP $(\mathrm{mg} / \mathrm{L})$ & $6.9 \pm 7.0$ \\
Cholesterol $(\mathrm{mg} / \mathrm{dL})$ & $181 \pm 57$ \\
Albumin $(\mathrm{g} / \mathrm{dL})$ & $4.2 \pm 0.8$ \\
Creatinine $(\mathrm{mg} / \mathrm{dL})$ & $7.0 \pm 2.0$ \\
Uric acid $(\mathrm{mg} / \mathrm{dL})$ & $5.4 \pm 2.8$ \\
\hline
\end{tabular}

for data normalization. The expression data throughout the paper are presented as $\Delta \Delta \mathrm{Ct}=$ mean $\Delta \mathrm{Ct}_{\text {ref }}-\Delta \mathrm{Ct}_{\text {sample }}$.

3.1. Statistical Analysis. Statistical analysis was performed with the Statistica v.12 statistical package (StatSoft, Poland). The numerical variables were tested for outliers and normality and presented as mean \pm standard deviation or median + interquartile range. In case of normally distributed variables, the Student $t$-test and regression were applied. If the normality assumption was not fulfilled, Mann-Whitney $U$-test and Spearman correlation were used. For normally distributed continuous variables, their influence on the outcome was corrected by multiple regression for the other parameters shown significantly in univariate analysis. $P<0.05$ was considered significant.

\section{Results}

4.1. Posttransplant Outcome. After transplantation, immediate kidney function was observed in $77 \%$ of the recipients. Delayed graft function (defined as a need of hemodialysis in the first week after transplantation) was seen in 20 cases (23\%). Seventeen recipients (19\%) experienced at least one biopsy-proven rejection episode within the first posttransplant year. Recipients were followed up for 5 years after transplantation. During that time 5 recipients died (5.7\%) and 11 lost their grafts (12\%). Severe cardiovascular complications occurred in 7 recipients (8\%), serious infections with a need of hospitalization occurred in 10 cases (11\%), 13 (15\%) recipients suffered from CMV disease, and 18 recipients (21\%) presented recurrent urinary tract infections. There was one case of malignant tumor.

After 24 months of observation $36 \%$ of recipients presented excellent kidney function with GFR above $50 \mathrm{~mL} / \mathrm{min}$ (mean GFR $60.3 \pm 5.4 \mathrm{~mL} / \mathrm{min}$ ).

\subsection{Pretransplant Clinical Parameters and Kidney Allograft} Outcome. Recipients and donors characteristics are included in Table 1 and the clinical pretransplant recipient blood parameters are presented in Table 2. All the parameters were analyzed in relation to graft short- and long-term outcome.

The pretransplant blood parameters (CRP, albumin, cholesterol, complete blood cell test, etc.) did not affect posttransplant outcome or acute rejection episodes. Time and type of previous renal replacement therapy-hemodialysis or peritoneal dialysis-did not influence outcome of transplantation. Moreover, in our study group, we found no association of cold ischemia time or number of HLA mismatches and graft function or survival.

From the clinical parameters studied only donor age, recipient age, and recipient BMI proved to influence allograft outcome.

Both recipients' and donors' age were negatively correlated with immediate and short- and long-term allograft function at any time point studied. Donor age was also a risk factor for delayed graft function and acute rejection. All significant correlations of clinical parameters with graft function are summarized in Table 4.

Recipients' age was associated with worse graft function from 14 days to 24 months (14-day GFR $r=-0.33, P=0.003$; 1-month GFR $r=-0.37, P=0.001$; 3-month GFR $r=-0.31$, $P=0.0 ; 6$-month GFR $r=-0.39, P=0.001 ; 12$-month GFR $r=-0.33, P=0.008$; and 24-month GFR $r=-0.35, P=$ 0.012 ).

Donor age was a strong risk factor for graft function deterioration from the beginning (14-day GFR $r=-0.33$, $P=0.004$; 1-month GFR $r=-0.41, P<0.001$; and 3-month GFR $r=-0.44, P<0.001)$ up to 24 months $(6$-month GFR $r=-0.60, P<0.001$; 12-month GFR $r=-0.48, P<0.001$; and 24-month GFR $r=-0.55, P<0.001)$. Donor age was also a risk factor for delayed graft function $(52.2 \pm 10.4$ versus $42.8 \pm 13.8 ; P=0.001)$ and acute rejection $(52.1 \pm 15.0$ versus $43.3 \pm 13.0 ; P=0.018)$.

Recipients' pretransplant BMI was negatively correlated with the short-term graft function from 3 up to 12 months (3month GFR $r=-0.35, P=0.009$; 6-month GFR $r=-0.36$, $P=0.010$; and 12-month GFR $r_{s}=-0.30, P=0.033$ ).

The correlation between the strongest clinical factors as donor age and recipient BMI with short-term kidney function (expressed by 6-month GFR) is presented in Figure 1.

4.3. Gene Expression. Gene expression in the peripheral blood stabilized in PaxBlood RNA tubes was studied with low density TaqMan arrays in triplicate. The observed expression levels are presented in Table 3. IL-17 gene expression was undetectable in all patients. Besides $I L-2$ all other genes expression values were normally distributed. The impact of $I L-2$ gene expression on graft function was analyzed with nonparametric statistics.

4.4. Correlations between Clinical Pretransplant Parameters and Gene Expression. No influence of recipient gender on gene expression was observed. Pretransplant white blood cell (WBC) affected expression of FOXP3, IL-2, LCN2, and TNF. Albumin level affected $I L-10$ expression. BMI was strongly correlated with LCN2 expression.

Significant correlations between clinical pretransplant parameters and gene expression are presented in Table 4.

4.5. Gene Expression Association with Graft Function: Univariate Analysis. We observed the association of some gene expression with subsequent graft function (Table 5). 


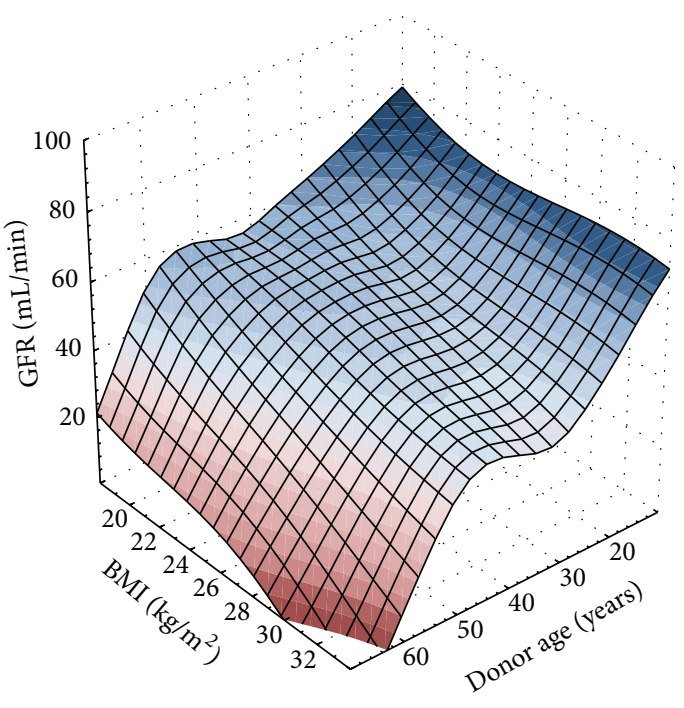

FIGURE 1: Best-fit surface representation of donor age and recipient BMI influence on graft function 6 months after transplantation.

TABLE 3: Expression level of the studied genes.

\begin{tabular}{lcccccc}
\hline Gene & Min. & $25 \%$ & Median & $75 \%$ & Max. & Mean \\
\hline CASP3 & -0.78 & 0.42 & 1.17 & 1.85 & 3.52 & 1.17 \\
FAS & -0.68 & 0.39 & 0.87 & 1.33 & 2.31 & 0.83 \\
FOXP3 & -0.6 & 0.37 & 0.91 & 1.37 & 2.31 & 0.88 \\
IFNG & -1.71 & 0.7 & 1.72 & 2.95 & 5.38 & 1.82 \\
IL-10 & -0.66 & 0.34 & 0.7 & 1.26 & 2.74 & 0.82 \\
IL-18 & -0.75 & 0.34 & 0.68 & 1.12 & 2.68 & 0.71 \\
IL-2 & -1.33 & 0.54 & 1.21 & 2.78 & 7.37 & 1.88 \\
IL-6 & -3.02 & 1.03 & 1.79 & 2.74 & 4.4 & 1.73 \\
IL-8 & -1.18 & 0.63 & 1.41 & 2.21 & 4.5 & 1.44 \\
LCN2 & -0.92 & 0.73 & 1.61 & 2.65 & 4.85 & 1.72 \\
TGFB1 & -0.43 & 0.27 & 0.41 & 0.67 & 1.25 & 0.43 \\
TNF & -0.56 & 0.36 & 0.67 & 0.97 & 1.56 & 0.63 \\
TP53 & -1 & 0.25 & 0.57 & 0.88 & 1.42 & 0.55 \\
\hline
\end{tabular}

TABLE 4: Significant correlations between pretransplant clinical parameters and gene expression.

\begin{tabular}{lccc}
\hline $\begin{array}{l}\text { Clinical } \\
\text { parameter }\end{array}$ & $\begin{array}{c}\text { Gene } \\
\text { expression }\end{array}$ & $\begin{array}{c}\text { Correlation } \\
\text { coefficient }\end{array}$ & $P$ \\
\hline WOXP3 & -0.30 & 0.020 \\
& FL-2 & -0.32 & 0.014 \\
& LCN2 & 0.28 & 0.026 \\
ALB & TNF & -0.34 & 0.008 \\
HGB & $I L-10$ & 0.27 & 0.025 \\
BMI & $I L-8$ & 0.29 & 0.021 \\
Recipient age & LCN2 & 0.45 & $<0.001$ \\
\hline
\end{tabular}

${ }^{*}$ Spearman correlation $r_{s}$ and probability.

4.6. Immediate Posttransplant Graft Function. TGFB1 exerted a negative influence on short-term graft function (14-day GFR $r=-0.24, P=0.039)$. Pretransplant $I L-2$ gene expression positively correlated with kidney function in the immediate posttransplant period (14-day GFR $r_{s}=0.24$, $P=0.040)$.

4.7. Short-Term Graft Function. LCN2 exerted a negative influence on short-term graft function (3-month GFR $r=$ $-0.27, P=0.024)$. From Th1-derived cytokines, IFNG was significantly upregulated in recipients with good kidney function at 6 months after $\operatorname{KTx}(r=0.27, P=0.029)$. From apoptosis-related genes CASP 3 and FAS were positively correlated with short-term graft function (CASP3: 6-month GFR $r=0.27, P=0.027$; FAS: 6-month GFR $r=0.28$, $P=0.021)$.

4.8. Long-Term Graft Function. The long-term kidney function described by eGFR from 12 months to 24 months was positively correlated with pretransplant expression of proapoptotic genes CASP3 and FAS (CASP3: 12-month GFR $r=0.3, P=0.016,24$-month GFR $r=0.41, P=0.003$, and FAS: 24-month GFR $r=0.3, P=0.033) .60$ months after transplantation CASP3 and IFNG association was still observed (CASP3 60-month GFR: $r_{s}=0.37, P=0.037$; IFNG 60-month GFR: $\left.r_{s}=0.27, P=0.024\right)$. Also $I L-18$ expression correlated positively with 5-year graft function (60-month GFR $\left.r_{s}=0.39, P=0.024\right)$. The fourth examined proapoptotic gene, TP53, did not correlate with graft function at any time point.

From Th1-derived cytokines, IFNG was significantly downregulated in recipients with bad clinical outcome from 12 to 24 months after KTx (12-month GFR: $r=0.3, P=0.018$, 24 -month GFR $r=0.29, P=0.04)$. Also pretransplant $I L$ 2 gene expression positively correlated with kidney function in the late period (18-month GFR $r_{s}=0.28, P=0.049 ; 60$ month GFR $r_{s}=0.41, P=0.026$, resp.).

We noted no association of expression of other examined genes with graft function at any time point. No correlation was observed between gene profiles and delayed graft function or acute rejection episode rates.

4.9. Gene Expression and Pretransplant Clinical Factors Association with Graft Function: Multivariate Analysis. As the particular time point GFR was influenced by a number of continuous variables, both clinical parameters (donor age, recipient age, and recipient $\mathrm{BMI}$ ) and gene expression (CASP3, FAS, IFNG, IL-18, TGFB1, and LCN2) multiple regression tests were performed. For each time point the parameters presenting significant correlation in simple regression analysis were included in multiple regression model as summarized in Table 5.

From the clinical factors donor age was the strongest risk factor for graft function deterioration from the beginning up to 24 months. Also recipient age was proved to be significant up to 12 months, and an association with BMI was shown 6 months after KTx.

TGFB1 gene expression was significantly and independently of donor and recipient age associated with the shortterm allograft function (14 days). IFNG association with 6month GFR was shown independently from donor age as well 
TABLE 5: Correlation of gene expression and pretransplant clinical parameters with GFR—simple and multiple linear regression analysis.

\begin{tabular}{|c|c|c|c|c|}
\hline & \multicolumn{2}{|c|}{ Simple regression } & \multicolumn{2}{|c|}{ Multiple regression* } \\
\hline & Corr. coeff. & $P$ & Corr. coeff & $P$ \\
\hline \multicolumn{5}{|l|}{ 14-day GFR } \\
\hline Recipient age & -0.33 & 0.003 & -0.27 & 0.012 \\
\hline Donor age & -0.33 & 0.004 & -0.29 & 0.008 \\
\hline TGFB1 & -0.24 & 0.039 & -0.25 & 0.016 \\
\hline \multicolumn{5}{|l|}{ 1-month GFR } \\
\hline Recipient age & -0.37 & 0.001 & -0.29 & 0.005 \\
\hline Donor age & -0.41 & 0.000 & -0.34 & 0.001 \\
\hline \multicolumn{5}{|l|}{ 3-month GFR } \\
\hline Recipient age & -0.31 & 0.010 & -0.18 & 0.176 \\
\hline Donor age & -0.44 & 0.000 & -0.29 & 0.028 \\
\hline BMI & -0.35 & 0.009 & -0.26 & 0.065 \\
\hline LCN2 & -0.27 & 0.024 & -0.15 & 0.256 \\
\hline \multicolumn{5}{|l|}{ 6-month GFR } \\
\hline Recipient age & -0.39 & 0.001 & -0.27 & 0.018 \\
\hline Donor age & -0.60 & 0.000 & -0.40 & 0.000 \\
\hline BMI & -0.36 & 0.010 & -0.38 & 0.001 \\
\hline CASP3 & 0.27 & 0.027 & 0.20 & 0.072 \\
\hline FAS & 0.28 & 0.021 & 0.09 & 0.405 \\
\hline IFNG & 0.27 & 0.029 & 0.32 & 0.003 \\
\hline \multicolumn{5}{|l|}{ 12-month GFR } \\
\hline Recipient age & -0.33 & 0.008 & -0.22 & 0.047 \\
\hline Donor age & -0.48 & 0.000 & -0.42 & 0.000 \\
\hline CASP3 & 0.30 & 0.016 & 0.23 & 0.038 \\
\hline IFNG & 0.30 & 0.018 & 0.23 & 0.034 \\
\hline \multicolumn{5}{|l|}{ 24-month GFR } \\
\hline Recipient age & -0.35 & 0.012 & -0.20 & 0.082 \\
\hline Donor age & -0.55 & 0.000 & -0.50 & 0.000 \\
\hline CASP3 & 0.41 & 0.003 & 0.34 & 0.003 \\
\hline FAS & 0.30 & 0.033 & 0.23 & 0.046 \\
\hline IFNG & 0.29 & 0.040 & 0.20 & 0.086 \\
\hline$I L-18$ & 0.28 & 0.044 & 0.23 & 0.047 \\
\hline
\end{tabular}

${ }^{*}$ Correlation coefficient for a clinical parameter was corrected for other clinical parameters and all listed genes influencing GFR at a given time point; each gene expression was corrected for all clinical parameters influencing GFR at a given time point.

as recipient age and BMI. This association was still observed 12 months after KTx. The proapoptotic CASP3 was shown to be associated positively with long-term graft function (12 and 24 months after KTx) independently from donor age. The association of other apoptosis-accelerating genes-FAS and $I L-18$ - was seen 24 months after KTx. The impact of LCN2 seen after 3 months in univariate analysis was not confirmed in multiple regression.

We also studied whether any of the expression levels of the three candidate genes: CASP3, FAS, and $I L-18$ could predict better long-term allograft function (eGFR $>50 \mathrm{~mL} / \mathrm{min} 24$ months after $\mathrm{KTx}$ ). The results of ROC analysis are shown in Table 6 . All of the three genes presented significant predictive value. Each of CASP3, FAS, and IL-18 gene expression levels above cut-off proved to have around $70 \%$ sensitivity and at least $80 \%$ specificity for good long-term outcome prediction.
TABLE 6: ROC analysis results for graft function (GFR $>50 \mathrm{~mL} / \mathrm{min}$ ) 24 months after KTx.

\begin{tabular}{lccccc}
\hline Gene & Cut-off & Sensitivity & Specificity & AUC & $P$ \\
\hline CASP3 & 1.613 & 0.71 & 0.88 & 0.79 & 0.0002 \\
FAS & 1.150 & 0.64 & 0.80 & 0.75 & 0.0029 \\
$I L-18$ & 0.781 & 0.71 & 0.80 & 0.77 & 0.0011 \\
\hline
\end{tabular}

\section{Discussion}

We studied the immune background of renal transplant candidates just before the transplantation and its impact on the transplant outcome. We analyzed the expression of immune-related genes at the mRNA level with real-time PCR methodology. We observed that Th1 derived cytokines (IL2 and IFN-gamma) were significantly correlated with better 
short- and long-term allograft function. We also observed a positive correlation between pretransplant expression of three proapoptotic genes, CASP3, FAS, and $I L-18$, with allograft function. Both of the observations were not published before. In addition, it is possible to hypothesize that some level of Thl constitutive activation supports more active apoptosis which in turn is associated with secretion of antiinflammatory, tolerogenic molecules as IL-10 and TGF-beta. Collectively, these observations could be interpretative as a credit for hypothesis that some basal immune system cell activation is needed to make them more sensitive to effective inhibition by immunosuppressive drugs.

Chronic kidney disease with progressive uremia is associated with both inflammation and immune deficiency. Primary activation of the innate immune system was noted. It was caused by abnormal function of regulatory T-cells, the depletion of dendritic cells, naive and central memory $\mathrm{T}$ cells and $\mathrm{B}$ cells, and impaired phagocytic function of polymorphonuclear cells and monocytes $[1,8,9]$.

Various studies have shown that pretransplant immune status of the recipient can influence transplant outcome, acute rejection episodes, delayed graft function, and kidney survival. It was noted that pretransplant humoral autoimmunity (cross matches, panel reactive antibodies) affected graft outcome [10]. Previously, we as well as other authors have reported that cellular alloimmunity measured by the ELISPOT technique influenced the acute rejection rate and overall graft survival $[11,12]$.

In our population the acute rejection rate was less than $20 \%$. Some studies observed that pretransplant blood cytokine pattern reflected immune infiltrates observed in kidney tissue during rejection. Similarly to some previous reports [7], we observed that none of the pretransplant cytokine patterns was associated with AR.

Th1 cytokines (IL-2, IFN-gamma) trigger an alloimmune response with activation of $\mathrm{T}$ cytotoxic lymphocytes, monocytes, and NK cells. Some author observed association between pretransplant Th1-derived cytokines and acute rejection episodes. Sadeghi et al. observed that high pretransplant IFN-gamma plasma levels were associated with acute rejection [13]. Pretransplant levels of anti-inflammatory cytokine TGF-beta tended to be lower among patients with acute rejection episodes, in contrast to upregulated Th1derived cytokines [6]. Pretransplant serum levels of another proinflammatory cytokine, IL-6, were associated with an increased risk of acute rejection episodes and graft loss [14], and sIL-6R was higher and TGF-beta was lower in patients exhibiting ATN [15]. Unexpectedly, it was noted that pretransplant elevations of not only proinflammatory IL-12, but also anti-inflammatory cytokine IL-10, were both connected to acute rejection [16].

In contrast there are few reports of no relationship of pretransplant cytokine levels with acute rejection incidence. Chin et al. observed that pretransplant IFN-gamma levels did not predict acute rejection in a small retrospective study [17]. Also Ghafari et al. found no significant difference in serum concentration of IL-2, IL-10, IL-4, and IFN-gamma on the day before transplantation between the group with acute rejection within the first months and rejection-free recipients [7]. Sadeghi et al. did not observe any influence of pretransplant levels of examined cytokines IL-1, IL-2, IL3, IL-4, IL-6, IL-10, TNF-alpha, TGF-beta, and IFN-gamma on acute rejection or ATN rate [15]. Among other conflicting reports we observed no correlation between immune factors' gene expression and acute rejection. Nevertheless in our study pretransplant gene expression of Th1-derived cytokines (IL-2 and IFNG) significantly correlated with better posttransplant allograft function from the beginning up to 5 years. According to our knowledge, no previous papers have reported an association between pretransplant cytokine expression and kidney allograft function measured by GFR.

Th1-derived cytokines trigger an alloimmune response but also are easily suppressed by standard immunosuppressive drugs (calcineurin inhibitors act by inhibiting $\mathrm{T}$ cells through IL-2 deprivation). Furthermore, it is known that IFN-gamma inhibits synthesis of the potent rejectionmaintaining cytokine IL-17 and further inhibits Th2 differentiation. This is a pathway of switching the alloresponse to a cellular rather than a humoral reaction. The humoral mechanism of rejection was recently described as more harmful and more difficult to manage than the cellular type. Graft failure has been described rarely after T-cell-mediated rejection and commonly after antibody-mediated rejection [18]. Moreover, some authors have observed elevated levels of IFN-gamma in stable patients after renal transplantation compared to an acute rejection group [13, 19]. That mechanism can partially explain our observation that higher pretransplant IFN-gamma expression was linked to better short- and long-term allograft function.

Apoptosis is an important mechanism of limiting immune response. We observed for the first time in the literature a positive correlation between pretransplant expression of three proapoptotic genes: for caspase-3, Fas, and IL-18 (CASP3, IL-18, and FAS), with allograft function expressed as eGFR. That association was seen not only in the early posttransplant period, but also in the long-term observation up to 5 years. Increased apoptosis of leukocytes was reported to be associated with increased proinflammatory activity in patients with chronic kidney disease. Fas, which is an apoptosis triggering cytokine, increased significantly with the stage of chronic kidney disease [20], especially in patients treated with peritoneal dialysis [21]. We did not find any published reports concerning expression of apoptosis-related genes in relation to further allograft function. In our study pretransplant expression of TP53, which belongs to the major apoptosis-inducing gene family, correlated negatively with WBC count. The majority of WBC are neutrophils. The chronic nonspecific immune reaction seen in uremia is mediated mainly by neutrophils [22]. The discovered positive correlation between proapoptotic gene expression and graft function may be partially explained by increased apoptosis of neutrophils and lymphocytes, which are known to be involved in the graft injury.

From the standard markers of inflammation, pretransplant CRP was reported to be a risk factor for acute rejection episodes [5] or not to influence graft function and survival among children [23] or adults [24]. In the present study 
we also found no influence of pretransplant CRP levels on the rate of delayed graft function or acute rejection and allograft function. After transplantation the restoration of renal function reduces the intensity of chronic inflammation in allograft recipients [25].

Severe pretransplant hypoalbuminemia was reported to be an independent risk factor for delayed graft function or graft loss $[4,26]$. In contrast, we did not find higher risk of posttransplant DGF, AR, or worse graft function in hypoalbuminemic recipients, possibly because the majority of our recipients presented pretransplant albumin levels within the normal range. We noted that the albumin level correlated significantly with IL-10 gene expression in our patients. This is an expected finding because hypoalbuminemia was described as a potent factor augmenting chronic inflammation [27-29].

In our study recipients' pretransplant BMI negatively correlated with the short-term graft function from 3 to 12 months. Contrary results were published on the association of a higher 1-year GFR with pretransplant obesity and lower early GFR in patients with BMI $<18.5 \mathrm{~kg} / \mathrm{m}^{2}$ [30]. More conflicting results on severe obesity and kidney allograft function were reported [31, 32]. Weissenbacher et al. found that recipient BMI correlated with the incidence of DGF and 1- and 5-year allograft function [33]. We did not find recipients' BMI to be a risk factor for acute rejection or DGF, probably because of low prevalence of obese and undernourished patients in our population (mean BMI was around $24 \mathrm{~kg} / \mathrm{m}^{2}$ ).

Among donor-related issues, age is one of the most important factors negatively influencing outcomes of kidney allografts [34]. Like other authors, we found a strong correlation between donor age and kidney function from the beginning up to 2 years.

Apart from nonspecific time-related injury, kidneys from older donors were proved to be associated with a more intense host immune response early after transplant (up to 1 month) reflected by significantly higher numbers of peripheral $\mathrm{T}$ and $\mathrm{B}$ cells, increased T-cell alloreactivity, and modified cytokine patterns in rats [35]. Allografts from older donors were reported to be more immunogenic than those from younger donors [36, 37]. In our study, donor age was an independent significant risk factor not only for delayed graft function but also for acute rejection, which is in agreement with previous reports. This deleterious influence was still noticeable despite the fact that the majority of our recipients (86\%) received grafts from donors younger than 60 years.

All the previously published results on the predictive value of pretransplant cytokine measurements were based on determination of cytokine blood concentration by ELISA technique. Our report for the first time assesses the cytokine gene expression in relation to posttransplant outcome. It was previously reported in a murine model that the IFN-gamma gene expression detected by real-time kinetic RT-PCR correlated very well with IFN-gamma protein secretion measured by ELISA [38]. Also Mohammadnia et al. examining serum levels of cytokines in kidney allograft recipients together with blood mRNA expression did not find any significant differences in those two ways of assessment of cytokine production [39]. Therefore our results reflect actual cytokine and other immune factors synthesis.

\section{Conclusion}

The study was performed to investigate whether pretransplant peripheral blood immune gene expression affects clinical outcome of renal allograft. The lowered pretransplant Th1derived cytokine and apoptosis-related gene expressions were a hallmark of subsequent worse kidney function but not of acute rejection rate. The pretransplant IFNG and CASP 3 and $F A S$ and $I L-18$ genes expression in the recipients' peripheral blood is the possible candidate for novel biomarker of shortand long-term allograft function.

\section{Abbreviations}

$\begin{array}{ll}\text { AR: } & \text { Acute rejection } \\ \text { BMI: } & \text { Body mass index } \\ \text { CIT: } & \text { Cold ischemia time } \\ \text { DGF: } & \text { Delayed graft function } \\ \text { eGFR: } & \text { Estimated glomerular filtration rate } \\ \text { ELISPOT: } & \text { Enzyme-Linked ImmunoSpot Assay } \\ \text { FAS: } & \text { First apoptotic signal } \\ \text { FOXP3: } & \text { Forkhead box P3 } \\ \text { GAPDH: } & \text { Glyceraldehyde 3-phosphate dehydrogenase } \\ \text { HD: } & \text { Hemodialysis } \\ \text { HLA: } & \text { Human leucocyte antigens } \\ \text { IFN-gamma: } & \text { Interferon gamma } \\ \text { IL-10: } & \text { Interleukin 10 } \\ \text { IL-18: } & \text { Interleukin 18 } \\ \text { IL-2: } & \text { Interleukin 2 } \\ \text { IL-6: } & \text { Interleukin } 6 \\ \text { IL-8: } & \text { Interleukin } 8 \\ \text { NGAL: } & \text { Neutrophil gelatinase-associated lipocalin } \\ \text { p53: } & \text { Tumor protein p53 } \\ \text { PCR: } & \text { Polymerase chain reaction } \\ \text { PD: } & \text { Peritoneal dialysis } \\ \text { PRA: } & \text { Panel reactive antibodies } \\ \text { TGF-beta: } & \text { Transforming growth factor beta } \\ \text { TNF-alpha: } & \text { Tumor necrosis factor alpha } \\ \text { WBC: } & \text { White blood cell. } \\ & \end{array}$

\section{Competing Interests}

All authors disclose no conflict of interests that might bias their work.

\section{Authors' Contributions}

Dorota Kamińska, Katarzyna Kościelska-Kasprzak, and Pawel Chudoba participated in research design, in the writing of the paper, in the performance of the research, and in data analysis. Oktawia Mazanowska, Mirosław Banasik, Marcelina Żabinska, Agnieszka Lepiesza, Agnieszka Gomółkiewicz, and Piotr Dzięgiel participated in the performance of the research. Marian Klinger participated 
in research design, in the writing of the paper, and in data analysis. Maria Boratyńska participated in research design.

\section{Acknowledgments}

This study was supported by a research grant from the Polish Society of Nephrology funded by Baxter.

\section{References}

[1] N. D. Vaziri, M. V. Pahl, A. Crum, and K. Norris, "Effect of uremia on structure and function of immune system," Journal of Renal Nutrition, vol. 22, no. 1, pp. 149-156, 2012.

[2] R. A. Zager, A. C. M. Johnson, and S. Lund, "Uremia impacts renal inflammatory cytokine gene expression in the setting of experimental acute kidney injury," American Journal of Physiology-Renal Physiology, vol. 297, no. 4, pp. F961-F970, 2009.

[3] T. Stompór, M. Pasowicz, W. Sułowicz et al., "An association between coronary artery calcification score, lipid profile, and selected markers of chronic inflammation in ESRD patients treated with peritoneal dialysis," American Journal of Kidney Diseases, vol. 41, no. 1, pp. 203-211, 2003.

[4] M. Z. Molnar, C. P. Kovesdy, S. Bunnapradist et al., "Associations of pretransplant serum albumin with post-transplant outcomes in kidney transplant recipients," American Journal of Transplantation, vol. 11, no. 5, pp. 1006-1015, 2011.

[5] A. Roshdy, M. M. El-Khatib, M. N. Rizk, and A. M. ElShehaby, "CRP and acute renal rejection: a marker to the point," International Urology and Nephrology, vol. 44, no. 4, pp. 12511255, 2012.

[6] M. Lessan-Pezeshki, A. Amirzargar, A. Fathi et al., "Value of pretransplantation cytokine profiles for predicting acute rejection in renal transplant recipients," Transplantation Proceedings, vol. 37, no. 7, pp. 2982-2984, 2005.

[7] A. Ghafari, K. Makhdoomi, P. Ahmadpour, A. T. Afshari, S. S. Lak, and L. Fakhri, "Serum T-lymphocyte cytokines cannot predict early acute rejection in renal transplantation," Transplantation Proceedings, vol. 39, no. 4, pp. 958-961, 2007.

[8] K. W. Kim, B. H. Chung, E. J. Jeon et al., "B cell-associated immune profiles in patients with end-stage renal disease (ESRD)," Experimental and Molecular Medicine, vol. 44, no. 8, pp. 465-472, 2012.

[9] S. Kato, M. Chmielewski, H. Honda et al., "Aspects of immune dysfunction in end-stage renal disease," Clinical Journal of the American Society of Nephrology, vol. 3, no. 5, pp. 1526-1533, 2008.

[10] P. C. Lee and M. Ozawa, "Reappraisal of HLA antibody analysis and crossmatching in kidney transplantation," Clinical Transplantation, pp. 219-226, 2007.

[11] O. Bestard, J. M. Cruzado, M. Lucia et al., "Prospective assessment of antidonor cellular alloreactivity is a tool for guidance of immunosuppression in kidney transplantation," Kidney International, vol. 84, no. 6, pp. 1226-1236, 2013.

[12] K. Koscielska-Kasprzak, D. Drulis-Fajdasz, D. Kaminska et al., "Pretransplantation cellular alloreactivity is predictive of acute graft rejection and 1-year graft function in kidney transplant recipients," Transplantation Proceedings, vol. 41, no. 8, pp. 30063008, 2009.

[13] M. Sadeghi, V. Daniel, R. Weimer, M. Wiesel, O. Hergesell, and G. Opelz, "Pre-transplant Th1 and post-transplant Th2 cytokine patterns are associated with early acute rejection in renal transplant recipients," Clinical Transplantation, vol. 17, no. 2, pp. 151-157, 2003.

[14] İ. Berber, B. Yiğit, G. Işıttmangil et al., "Evaluation of pretransplant serum cytokine levels in renal transplant recipients," Transplantation Proceedings, vol. 40, no. 1, pp. 92-93, 2008.

[15] M. Sadeghi, V. Daniel, C. Naujokat, A. Mehrabi, and G. Opelz, "Association of high pretransplant sIL-6R plasma levels with acute tubular necrosis in kidney graft recipients," Transplantation, vol. 81, no. 12, pp. 1716-1724, 2006.

[16] J. T. Fitzgerald, J. R. Johnson, and R. V. Perez, "Pre-transplant elevations of interleukin-12 and interleukin-10 are associated with acute rejection after renal transplantation," Clinical Transplantation, vol. 18, no. 4, pp. 434-439, 2004.

[17] G. K. Chin, C. L. Adams, B. S. Carey, S. Shaw, W.-Y. Tse, and E. R. Kaminski, "The value of serum neopterin, interferon-gamma levels and interleukin-12B polymorphisms in predicting acute renal allograft rejection," Clinical and Experimental Immunology, vol. 152, no. 2, pp. 239-244, 2008.

[18] J. Sellarés, D. G. de Freitas, M. Mengel et al., "Understanding the causes of kidney transplant failure: the dominant role of antibody-mediated rejection and nonadherence," American Journal of Transplantation, vol. 12, no. 2, pp. 388-399, 2012.

[19] M. Karczewski, J. Karczewski, B. Poniedzialek, K. Wiktorowicz, M. Smietanska, and M. Glyda, "Distinct cytokine patterns in different states of kidney allograft function," Transplantation Proceedings, vol. 41, no. 10, pp. 4147-4149, 2009.

[20] E. Dounousi, E. Koliousi, A. Papagianni et al., "Mononuclear leukocyte apoptosis and inflammatory markers in patients with chronic kidney disease," American Journal of Nephrology, vol. 36, no. 6, pp. 531-536, 2012.

[21] D. Kaminska, K. Koscielska-Kasprzak, P. Chudoba et al., “Type of renal replacement therapy (hemodialysis versus peritoneal dialysis) does not affect cytokine gene expression or clinical parameters of renal transplant candidates," BioMed Research International, vol. 2015, Article ID 797490, 7 pages, 2015.

[22] M. Chonchol, "Neutrophil dysfunction and infection risk in end-stage renal disease," Seminars in Dialysis, vol. 19, no. 4, pp. 291-296, 2006.

[23] L. Butani, J. Johnson, C. Troppmann, J. McVicar, and R. V. Perez, "Predictive value of pretransplant inflammatory markers in renal allograft survival and rejection in children," Transplantation Proceedings, vol. 37, no. 2, pp. 679-681, 2005.

[24] M. Varagunam, H. Finney, R. Trevitt et al., "Pretransplantation levels of C-reactive protein predict all-cause and cardiovascular mortality, but not graft outcome, in kidney transplant recipients," American Journal of Kidney Diseases, vol. 43, no. 3, pp. 502-507, 2004.

[25] E. M. Simmons, A. Langone, M. T. Sezer et al., "Effect of renal transplantation on biomarkers of inflammation and oxidative stress in end-stage renal disease patients," Transplantation, vol. 79, no. 8, pp. 914-919, 2005.

[26] D. J. Tancredi and L. Butani, "Pretransplant serum albumin is an independent predictor of graft failure in pediatric renal transplant recipients," Journal of Pediatrics, vol. 164, no. 3, pp. 602-606, 2014.

[27] J. Gupta, N. Mitra, P. A. Kanetsky et al., "Association between albuminuria, kidney function, and inflammatory biomarker profile in CKD in CRIC," Clinical journal of the American Society of Nephrology, vol. 7, no. 12, pp. 1938-1946, 2012.

[28] K. Kalantar-Zadeh, J. D. Kopple, G. Block, and M. H. Humphreys, "A malnutrition-inflammation score is correlated 
with morbidity and mortality in maintenance hemodialysis patients," American Journal of Kidney Diseases, vol. 38, no. 6, pp. 1251-1263, 2001.

[29] I. Beberashvili, A. Azar, I. Sinuani et al., "Objective Score of Nutrition on Dialysis (OSND) as an alternative for the malnutrition-inflammation score in assessment of nutritional risk of haemodialysis patients," Nephrology Dialysis Transplantation, vol. 25, no. 8, pp. 2662-2671, 2010.

[30] M. M. Abou-Jaoude, N. Nawfal, R. Najm, M. Honeidi, J. Shaheen, and W. Y. Almawi, "Effect of pretransplantation body mass index on allograft function and patient survival after renal transplantation," Transplantation Proceedings, vol. 42, no. 3, pp. 785-788, 2010.

[31] Y. Lebranchu, C. Baan, L. Biancone et al., "Pretransplant identification of acute rejection risk following kidney transplantation," Transplant International, vol. 27, no. 2, pp. 129-138, 2014.

[32] N. N. Massarweh, J. L. Clayton, C. A. Mangum, S. S. Florman, and D. P. Slakey, "High body mass index and short- and longterm renal allograft survival in adults," Transplantation, vol. 80, no. 10, pp. 1430-1434, 2005.

[33] A. Weissenbacher, M. Jara, H. Ulmer et al., "Recipient and donor body mass index as important risk factors for delayed kidney graft function," Transplantation, vol. 93, no. 5, pp. 524529, 2012.

[34] F. Oppenheimer, P. Aljama, C. Asensio Peinado, J. Bustamante Bustamante, J. F. Crespo Albiach, and L. Guirado Perich, "The impact of donor age on the results of renal transplantation," Nephrology Dialysis Transplantation, vol. 19, supplement 3, pp. iiil1-iii15, 2004.

[35] A. Reutzel-Selke, A. Jurisch, C. Denecke et al., "Donor age intensifies the early immune response after transplantation," Kidney International, vol. 71, no. 7, pp. 629-636, 2007.

[36] J. Pratschke, V. Merk, A. Reutzel-Selke et al., "Potent early immune response after kidney transplantation in patients of the European senior transplant program," Transplantation, vol. 87, no. 7, pp. 992-1000, 2009.

[37] D. E. Hricik, E. D. Poggio, K. J. Woodside et al., "Effects of cellular sensitization and donor age on acute rejection and graft function after deceased-donor kidney transplantation," Transplantation, vol. 95, no. 10, pp. 1254-1258, 2013.

[38] J. Hein, U. Schellenberg, G. Bein, and H. Hackstein, "Quantification of murine IFN- $\gamma$ mRNA and protein expression: impact of real-time kinetic RT-PCR using SYBR green I dye," Scandinavian Journal of Immunology, vol. 54, no. 3, pp. 285-291, 2001.

[39] M. Mohammadnia, G. Solgi, M. Ranjbar et al., "Serum levels of interleukin (IL)-10, IL-17, transforming growth factor (TGF)$\beta 1$, and interferon- $\gamma$ cytokines and expression levels of IL-10 and TGF- $\beta 1$ genes in renal allograft recipients after donor bone marrow cell infusion," Transplantation Proceedings, vol. 43, no. 2, pp. 495-499, 2011. 


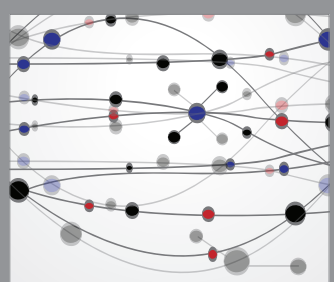

The Scientific World Journal
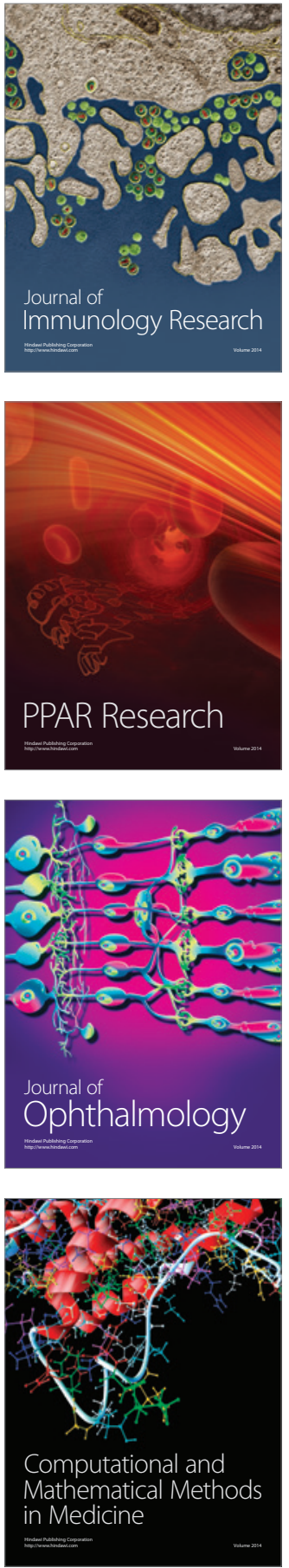

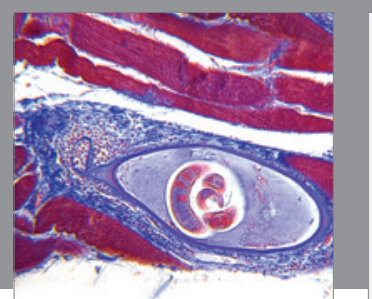

Gastroenterology Research and Practice

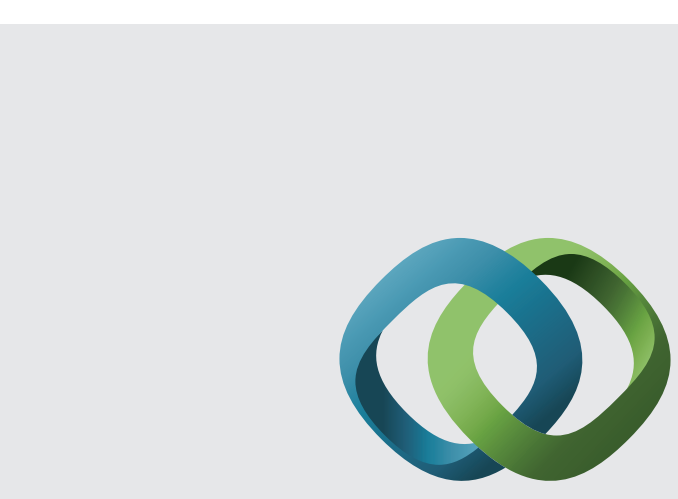

\section{Hindawi}

Submit your manuscripts at

http://www.hindawi.com
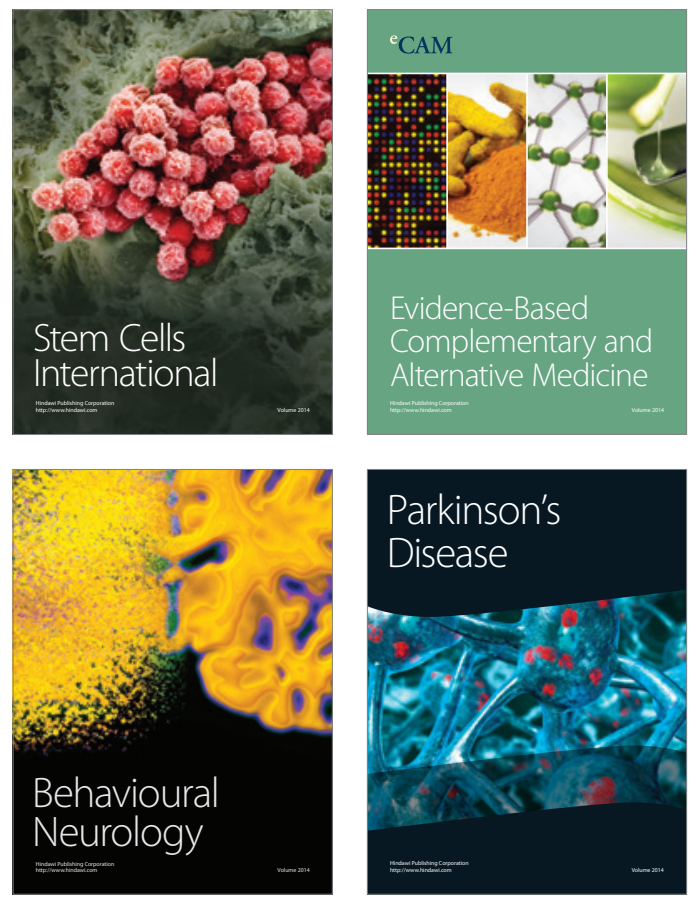
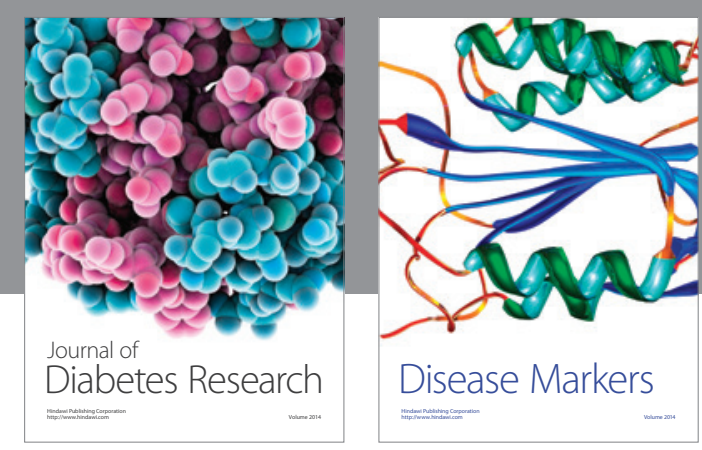

Disease Markers
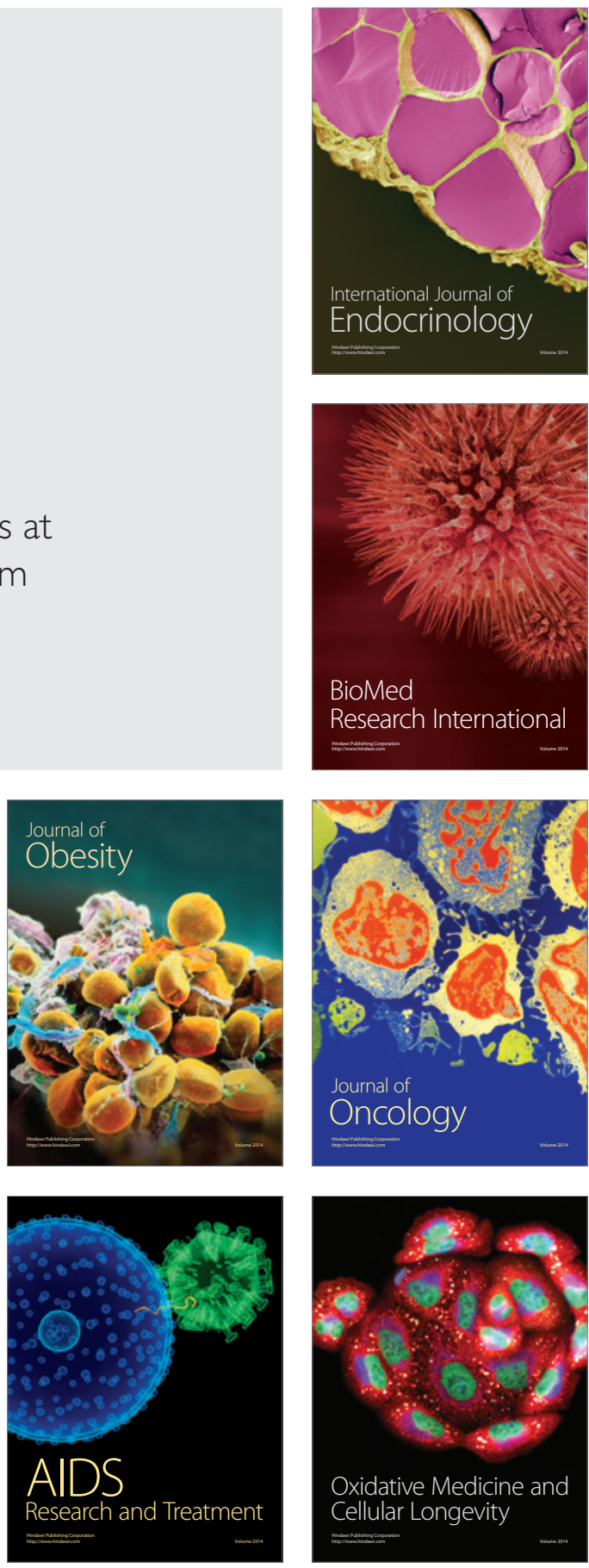